\title{
Association between MMP2-1306 C/T polymorphism and prostate cancer susceptibility: a meta-analysis based on 3906 subjects
}

\author{
Kaiping Zhang ${ }^{1}$, Xianguo Chen ${ }^{2}$, Jun Zhou ${ }^{2}$, Cheng Yang', Meng Zhang ${ }^{2}$, Min Chao', \\ Li Zhang' and Chaozhao Liang ${ }^{2}$ \\ ${ }^{1}$ Department of Urology, Anhui Provincial Children's Hospital, Hefei, Anhui, China \\ 2 Department of Urology, The First Affiliated Hospital of Anhui Medical University and Institute of Urology, AHMU, Hefei, \\ Anhui, China \\ Correspondence to: Chaozhao Liang, email: liang_chaozhao@163.com
}

Li Zhang, email: Izhang@ahmu.edu.cn

Min Chao, email: cm0654@sina.com

Keywords: MMP2, polymorphism, prostate cancer, susceptibility, Gleason grading

Received: September 14, $2016 \quad$ Accepted: March 14, $2017 \quad$ Published: April 08, 2017

Copyright: Zhang et al. This is an open-access article distributed under the terms of the Creative Commons Attribution License 3.0 (CC BY 3.0), which permits unrestricted use, distribution, and reproduction in any medium, provided the original author and source are credited.

\section{ABSTRACT}

Numerous investigations have addressed the correlation between MMP2-1306C/T polymorphism and prostate cancer ( $\mathrm{PCa}$ ) susceptibility. However, these conclusions were controversial. Thus, we conducted this current meta-analysis based on six studies from PubMed, Embase, Cochrane Library, China Biology Medicine disc (CBM), China National Knowledge Infrastructure (CNKI) up to October 21st, 2016. Odds ratios (ORs) with $95 \%$ confidence intervals (CIs) were calculated to evaluate the strength of the correlations. Additionally, different subgroup analyses and publication bias tests were performed. Eventually, six previous investigations consisted of 1920 cases and 1986 controls were identified and involved in this meta-analysis. Consequently, our evidence indicates a certain association between MMP2-1306C/T polymorphism and PCa risk among overall population (T vs C: $O R=1.12,95 \% \mathrm{CI}=1.00-1.24, P=$ 0.040 ; TT+CT vs CC: $O R=1.16,95 \% C I=1.02-1.32, P=0.026$; respectively), as well as the subgroups of Asian population ( $T$ vs $C$ : $O R=1.48,95 \% C I=1.13-1.94, P=0.004$; TT+CT vs CC: $O R=1.66,95 \% C I=1.21-2.28, P=0.002$; respectively) and PCR-RFLP genotyped method $(T$ vs $C$ : $O R=1.58,95 \% C I=1.19-2.10, P=0.001 ;$ TT $+C T$ vs CC: $O R=1.71,95 \% C I=1.23-2.38, P=0.001 ;$ respectively). However, no association was detected in MMP2-1306C/T polymorphism with Gleason grading or pathological stage of PCa. Our study indicates MMP2-1306 C/T polymorphism might increase PCa risk, particularly for Asian population. However, future studies comprising large cohort size from multicenter are required to confirm our conclusions.

\section{INTRODUCTION}

Prostate cancer $(\mathrm{PCa})$ is the primary cause of cancerrelated death which seriously threatens psychological and physical health in older men. PCa characterized by high incidence and mortality rate has drawn extensive attention in clinic. An estimation of 2015 cancer statistics revealed 220,800 new patients and 27,540 new deaths assigned to $\mathrm{PCa}$ [1]. Whereas, the mechanisms of carcinogenesis were still largely unexplored. It is well-established that both environmental factors and genetic diversities have non-negligible influences upon prostatic carcinogenesis. Genome-wide association studies have detected different single nucleotide polymorphisms (SNPs) correlated with PCa susceptibility [2]. It has also been proven that additional independent SNPs at GWAS-identified loci were closely linked with $\mathrm{PCa}$ [3-5]. To our best knowledge, several genetic mutations including nuclear factor kappa $B(N F-\kappa B), p 53$ along with $M M P s$ have been identified, which raised major concerns regarding the roles 
of gene polymorphisms in carcinogenesis during past decades [6-8].

Matrix metalloproteinases (MMPs) belonged to extracellular matrix (ECM)-degrading enzymes participated in the mechanisms of inflammation and angiogenesis [9]. To date, preclinical researches revealed that these MMPs had great potential in cardiovascular disease therapy and diabetes biomarkers screening [10-11]. As for cancers, MMPs have been shown as characteristic sign of tumor invasion and prognosis [12]. Matrix metalloproteinase 2 (MMP2) has been extensively studied in MMPs. It is well known that MMP2 has a positive influence upon the cancerous progression which may be involved in tumor growth, invasion and metastasis [13]. The MMP2 gene, located at Chromosome 16, is composed of 13 exons. Its polymorphism may be linked with different cancer risks owing to reduced enzymic activity [14]. Although several studies have shown that MMP2$1306 \mathrm{C} / \mathrm{T}$ polymorphism might be closely associated with PCa development, the conclusions were not consistent yet, which results could be explained by the relatively small samples in each published study. Additionally, MMP2 is upregulated in $\mathrm{PCa}$, and higher abundance may indicate poorer prognosis [15]. Meta-analysis can explore the authentic and comprehensive results through incorporating all available evidences to get a relatively precise and accurate estimation using statistical software [16]. Herein, we conduct a meta-analysis to assess the possible correlations between $M M P 2-1306 C / T$ polymorphism and $\mathrm{PCa}$ risk, which efforts should hold great promise in the clinical diagnosis and therapy for PCa.

\section{RESULTS}

\section{Characteristics of eligible studies}

Eventually, six studies consisted of 1920 cases and 1986 controls satisfied the eligible studies (Figure 1) [17-22]. Of the six studies, three White and three Asian population were estimated. The sample sizes ranged from 104 to 2867. Meanwhile, two Taqman, three PCR-RFLP and one HRM in genotyped approaches were introduced. Based on the control source, one was BPH and five were healthy PB as controls. The HWE of control were then evaluated among eligible studies. All PCa samples were histologically diagnosed. The relevant characteristics were shown in Table 1.

\section{Meta-analysis result}

\section{Meta-analysis for $M M P 2-1306 C / T$ polymorphism with PCa}

Finally, six studies consisted of 1920 cases and 1986 controls enrolled in this analysis using randomor fixed-effects model. Consequently, the pooled data indicated a certain association between $M M P 2-1306 C / T$ polymorphism with $\mathrm{PCa}$ risk among overall population (T vs $\mathrm{C}: \mathrm{OR}=1.12,95 \% \mathrm{CI}=1.00-1.24, P=0.040 ; \mathrm{TT}+\mathrm{CT}$ vs
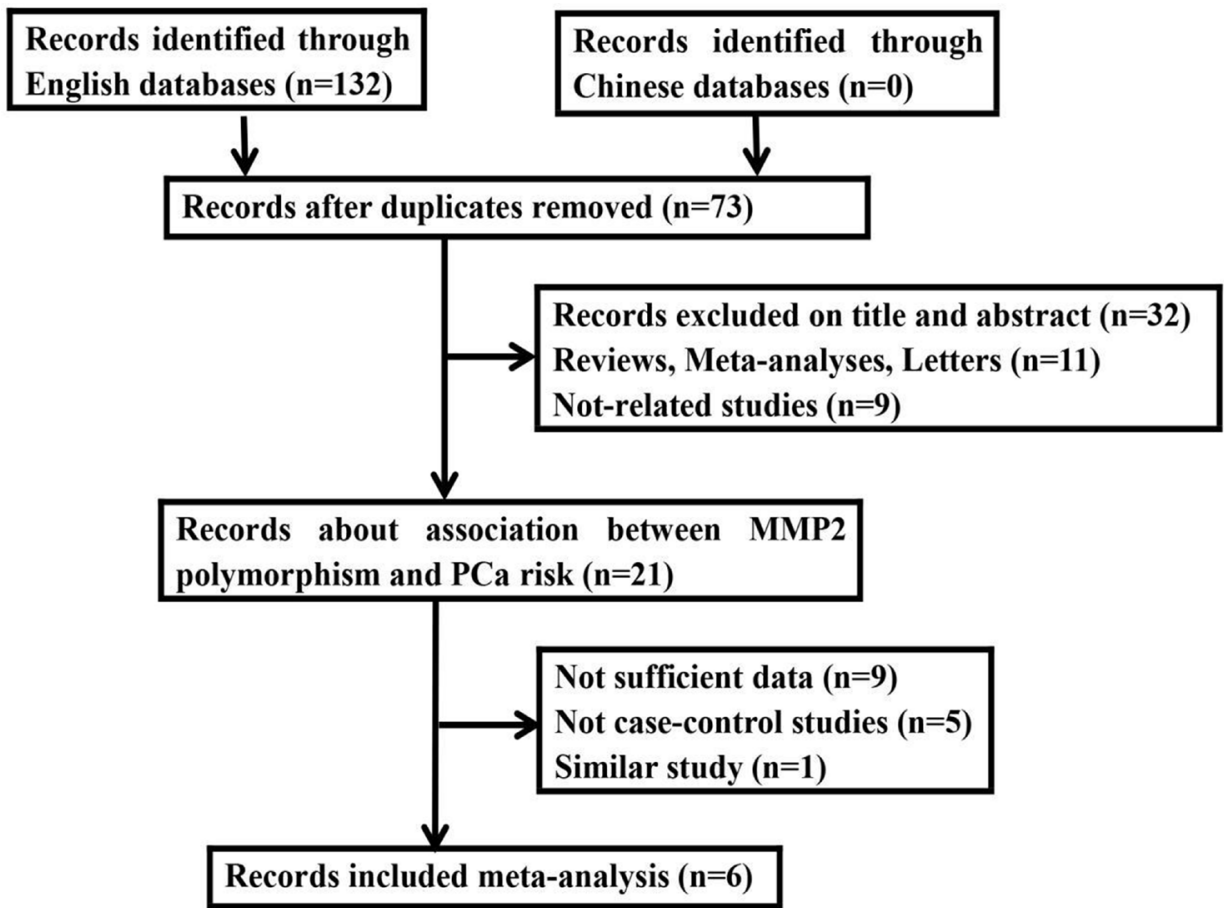

Figure 1: Flow diagram of the study selection process in the meta-analysis. 
Table 1: Main characteristics of studies regarding the association between $M M P 2-1306 C / T$ polymorphism and prostate cancer risk.

\begin{tabular}{|c|c|c|c|c|c|c|c|c|c|c|}
\hline Polymorphism & Authors & Year & Country & Ethnicity & $\begin{array}{l}\text { Genotyped } \\
\text { method }\end{array}$ & $\begin{array}{l}\text { Source } \\
\text { of } \\
\text { control }\end{array}$ & Association & $\begin{array}{l}\text { Case/ } \\
\text { Control }\end{array}$ & HWE & NOS \\
\hline \multirow{6}{*}{$M M P 2-1306 C / T$} & $\begin{array}{l}\text { Shajarehpoor S } \\
\text { et al. [17] }\end{array}$ & 2016 & Iran & Asian & HRM & PB & No & $50 / 54$ & NO & 7 \\
\hline & $\begin{array}{l}\text { Adabi } \\
\text { et al. [18] }\end{array}$ & 2015 & Iran & Asian & PCR-RFLP & $\mathrm{BPH}$ & No & $101 / 137$ & Yes & 7 \\
\hline & \begin{tabular}{|l} 
Yayksali \\
et al. [19]
\end{tabular} & 2014 & Turkey & White & PCR-RFLP & PB & No & $61 / 46$ & Yes & 8 \\
\hline & $\begin{array}{l}\text { Srivastava } \\
\text { et al. [20] }\end{array}$ & 2012 & North India & Asian & PCR-RFLP & $\mathrm{PB}$ & Yes & $190 / 200$ & Yes & 8 \\
\hline & \begin{tabular}{|l|} 
Dos Reis \\
et al. [21] \\
\end{tabular} & 2008 & Brazil & White & TaqMan & PB & Yes & $100 / 100$ & No & 7 \\
\hline & \begin{tabular}{|l} 
Jacobs \\
et al. [22]
\end{tabular} & 2008 & America & White & TaqMan & PB & Yes & $1418 / 1449$ & Yes & 7 \\
\hline
\end{tabular}

PB population-based; BPH benign prostatic hyperplasia; HWE Hardy-Weinberg equilibrium of control; PCR-RFLP polymerase chain reaction and restriction fragment length polymorphism; HRM high-resolution melting analysis; NOS Newcastle-Ottawa Scale.

$\mathrm{CC}: \mathrm{OR}=1.16,95 \% \mathrm{CI}=1.02-1.32, P=0.026$; respectively) (Figure 2).

Subgroup analyses underlying the ethnicity, source of control and genotyped method were carried out. As a result, a certain association was detected in Asian population (T vs $\mathrm{C}$ : $\mathrm{OR}=1.48,95 \% \mathrm{CI}=1.13-1.94, P=$ 0.004 ; $\mathrm{TT}+\mathrm{CT}$ vs $\mathrm{CC}: \mathrm{OR}=1.66,95 \% \mathrm{CI}=1.21-2.28$, $P=0.002$; respectively) and in PCR-RFLP genotyped method (T vs $\mathrm{C}: \mathrm{OR}=1.58,95 \% \mathrm{CI}=1.19-2.10, P=$
0.001; $\mathrm{TT}+\mathrm{CT}$ vs $\mathrm{CC}: \mathrm{OR}=1.71,95 \% \mathrm{CI}=1.23-2.38, P=$ 0.001 ; respectively). Conversely, there were no significant associations among other subgroups (Table 2).

\section{Meta-analysis for $M M P 2-1306 C / T$ polymorphism with Gleason grade and pathological stage}

Among the previous eligible studies, only four studies have been performed to explore the correlations

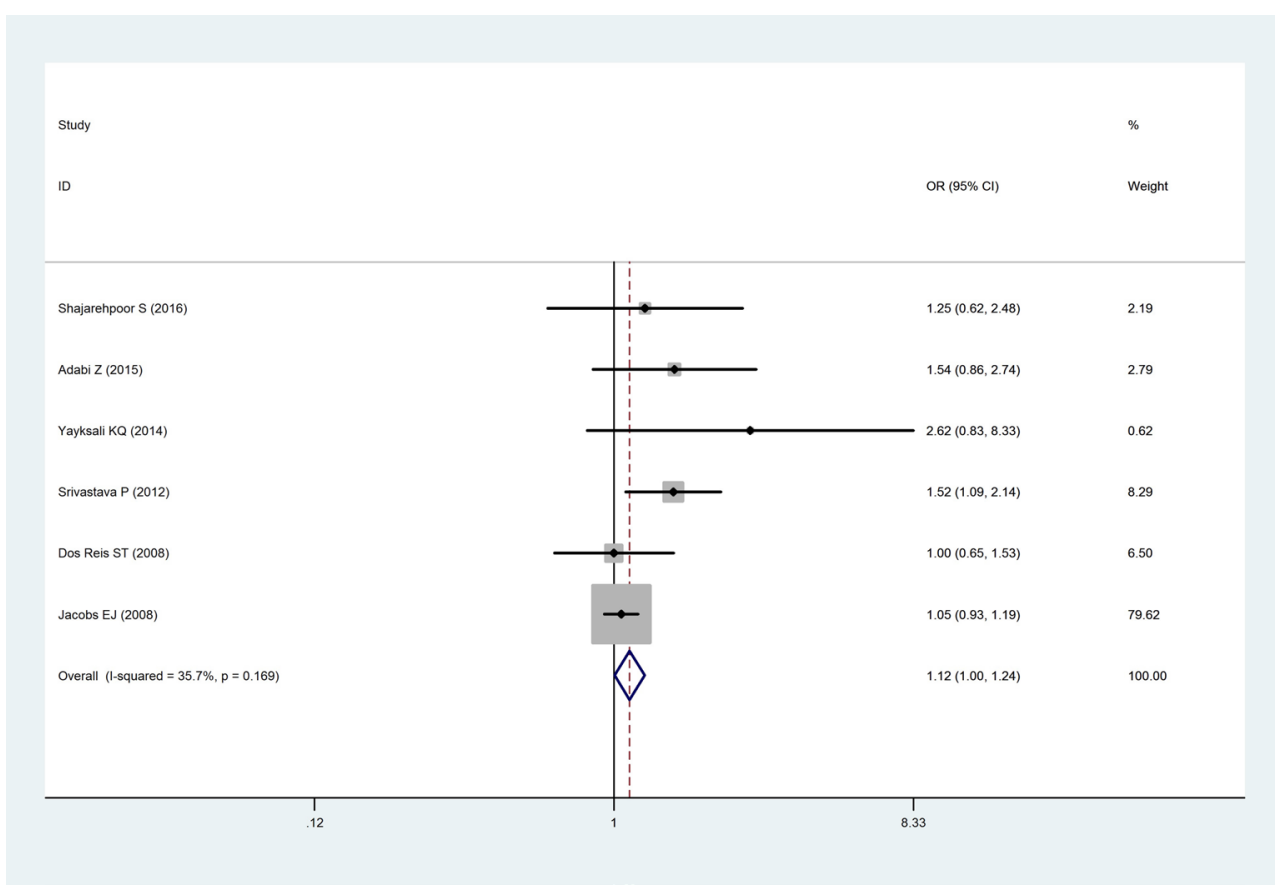

Figure 2: Forest plot for the meta-analysis of the association between $M M P 2-1306 C / T$ polymorphism with PCa risk under allele comparison model with fixed-effects model. The squares and horizontal lines correspond to the study-specific OR and $95 \%$ CI. The area of the squares reflects the weight. The diamond represents the summary OR and $95 \%$ CI. CI $=$ confidence interval, $\mathrm{OR}=$ odds ratio. 
Table 2: Stratified analysis of the $M M P 2-1306 C / T$ polymorphism and prostate cancer.

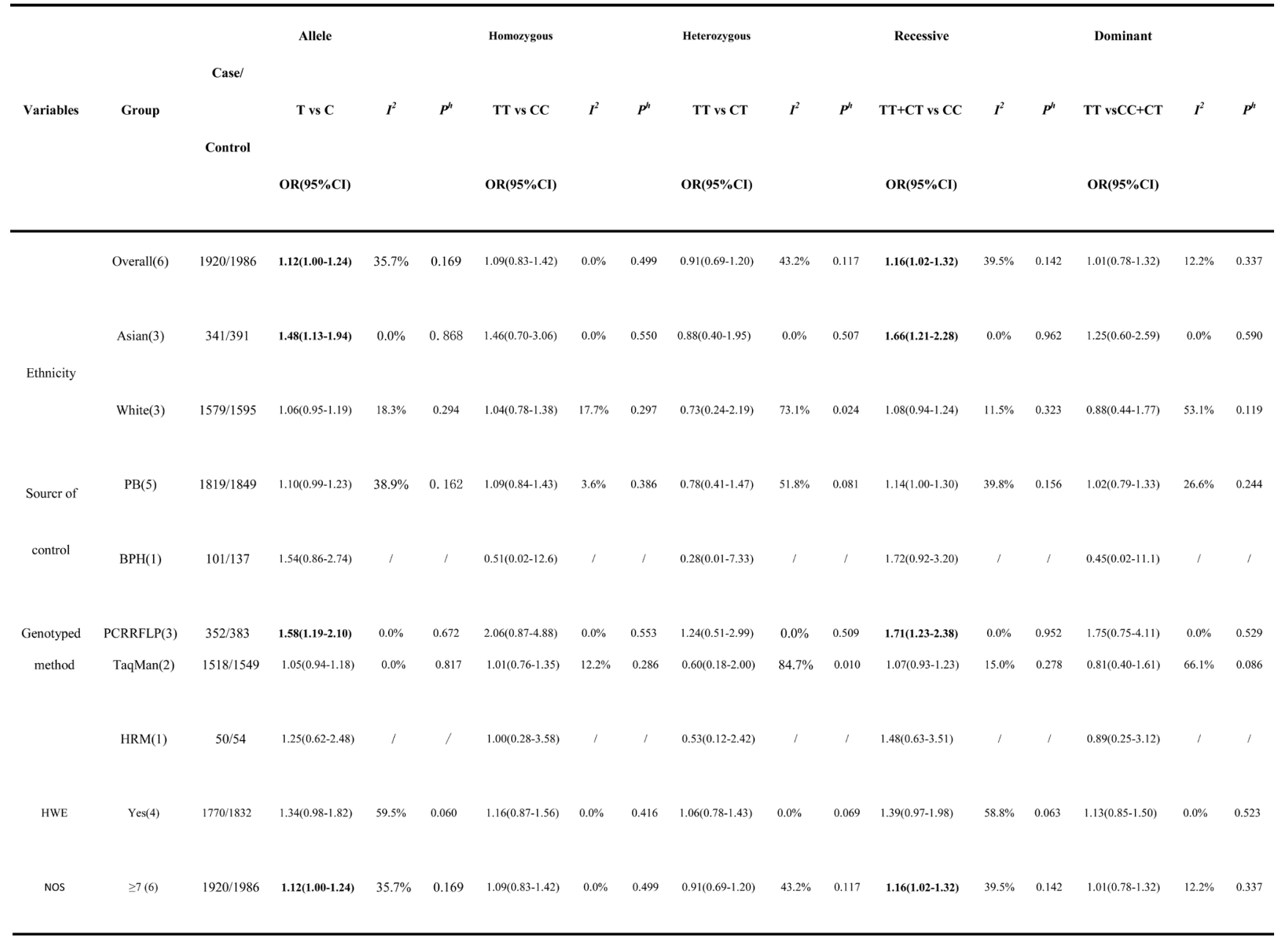

OR odds ratio; CI confidence interval; $P^{\text {h }} P$-value of heterogeneity test; HWE Hardy-Weinberg equilibrium of control.

between $M M P 2-1306 C / T$ polymorphism with different Gleason group grades [17-18, 20-21]. Patients were categorized into Gleason $\geq 7$ and Gleason $<7$. Overall, no statistically significant association was observed in $M M P 2-1306 C / T$ polymorphism with any of the Gleason grading of $\mathrm{PCa}$ ( $\mathrm{T}$ vs $\mathrm{C}: \mathrm{OR}=1.23,95 \% \mathrm{CI}=0.85-1.78$, $P=0.264 ;$ TT vs $\mathrm{CC}: \mathrm{OR}=1.88,95 \% \mathrm{CI}=0.74-4.80, P$ $=0.185$; TT vs CT: $\mathrm{OR}=1.57,95 \% \mathrm{CI}=0.60-4.11, P=$ $0.355 ; \mathrm{CT}+\mathrm{TT}$ vs CC: $\mathrm{OR}=1.19,95 \% \mathrm{CI}=0.75-1.87, P$ $=0.461$; TT vs CC+CT: $\mathrm{OR}=1.77,95 \% \mathrm{CI}=0.72-4.35$, $P=0.216$; respectively). When analyzing pathological stage, there were only two related studies $[17,21]$. Patients were divided into $\mathrm{pT}_{3}$ and $\mathrm{pT}_{2}$, and no association between $M M P 2-1306 C / T$ polymorphism or pathological stage was addressed (T vs $\mathrm{C}: \mathrm{OR}=1.33,95 \% \mathrm{CI}=0.43-4.10, P=$ 0.622; TT vs CC: $\mathrm{OR}=1.39,95 \% \mathrm{CI}=0.14-14.04, P=$ 0.782; TT vs CT: $\mathrm{OR}=0.94,95 \% \mathrm{CI}=0.30-2.93, P=$ 0.910; $\mathrm{CT}+\mathrm{TT}$ vs $\mathrm{CC}: \mathrm{OR}=1.69,95 \% \mathrm{CI}=0.51-5.65, P$ $=0.393$; TT vs CC+CT: OR $=1.12,95 \% \mathrm{CI}=0.18-6.93$, $P=0.900$; respectively). (Table 3 )

\section{Sensitivity analysis}

Herein, each single study was deleted at a time to assess the specific effect of the individual data on the pooled ORs, and one-way sensitivity analysis revealed that pooled results were relatively stable (Figure 3 ).

\section{Publication bias evaluation}

Begg's funnel plot indicated that publication bias was not found in allele of $M M P 2-1306 C / T$ polymorphism $(P=0.452$, Figure 4). Meanwhile, no publication bias was found in each subgroup of mata-analysis.

\section{DISCUSSION}

Until now, investigations focused on the correlations between $M M P 2-1306 C / T$ polymorphism with $\mathrm{PCa}$ were relatively rare and inconclusive. Meanwhile, small 
Table 3: Meta-analysis for $M M P 2-1306 C / T$ polymorphism with Gleason grade and pathological stage

\begin{tabular}{|l|l|l|l|l|l|l|}
\hline \multirow{2}{*}{ Comparison } & \multicolumn{3}{|c}{ Gleason grade } & \multicolumn{2}{c|}{ pathological stage } \\
\cline { 2 - 7 } & \multicolumn{1}{|c|}{ OR(95\%CI) } & \multicolumn{1}{|c|}{$\mathbf{I}^{\mathbf{2}}$} & \multicolumn{1}{|c|}{$\mathbf{P}^{\mathbf{h}}$} & \multicolumn{1}{c|}{ OR(95\%CI) } & $\mathbf{I}^{\mathbf{2}}$ & $\mathbf{P}^{\mathbf{h}}$ \\
\hline T $v s$ C & $1.23(0.85-1.78)$ & $1.8 \%$ & 0.383 & $1.33(0.43-4.10)$ & $71.7 \%$ & 0.060 \\
\hline TT $v s$ CC & $1.88(0.74-4.80)$ & $26.1 \%$ & 0.258 & $1.39(0.14-14.04)$ & $67.4 \%$ & 0.782 \\
\hline TT $v s$ CT & $1.57(0.60-4.11)$ & $23.6 \%$ & 0.270 & $0.94(0.30-2.93)$ & $10.8 \%$ & 0.290 \\
\hline CT+TT $v s$ CC & $1.19(0.75-1.87)$ & $0.0 \%$ & 0.692 & $1.69(0.51-5.65)$ & $59.2 \%$ & 0.117 \\
\hline TT $v s$ CC+CT & $1.77(0.72-4.35)$ & $29.7 \%$ & 0.241 & $1.12(0.18-6.93)$ & $52.6 \%$ & 0.146 \\
\hline
\end{tabular}

$\mathrm{P}^{\mathrm{h}} \mathrm{P}$-value of heterogeneity test.

sample-sized studies lacking statistical power often result in apparently contradictory conclusions. Meta-analysis is an useful tool for providing convincing evidence as it could present inconsistent results from different investigations to obtain a relatively precise estimation. As far as we know, the current meta-analysis is the first try to comprehensively assess the correlation between $M M P 2$ $1306 C / T$ gene polymorphism with $\mathrm{PCa}$ risk. Besides, the potential associations were explored in different subgroups. Consequently, the current meta-analysis revealed a certain relationship between $M M P 2-1306 C / T$ polymorphism and $\mathrm{PCa}$ in overall group together with the subgroup of Asian population and PCR-RFLP genotyped method. However, no significant association was observed in $M M P 2-1306 C / T$ polymorphism with Gleason grading or pathological stage of PCa.

Due to significant heterogeneity of the current meta-analysis, careful interpretation and search for influencing factors were required. Through different subgroups analyses, differences in the ethnicity and genotyped method should be considered as potential sources of heterogeneity. Additionally, sample size may have an impact on heterogeneity. It is well-established that formalin-fixation and/or prolonged storage could elicit damage to nucleic acids, further conferring considerable limitation on results [23-24]. Besides, other undiscovered factors should also be taken into consideration in advanced researches.

Recently, the associations between MMP2 polymorphisms with cancers have been extensively explored in published meta-analyses. Whereas, these results differed greatly in various types of cancer. For instance, no associations were identified between $M M P$ $2-1306 C / T$ polymorphism with susceptibility of breast cancer, colorectal cancer and gastric cancer, respectively in previous meta-analyses [25-27]. In addition, $M M P 1$, $M M P 3$ and $M M P 9$ polymorphisms were not linked with colorectal cancer susceptibility [27]. Moreover, no significant relationships of $M M P-2-1306$ and -735 C/T polymorphisms were found with coronary artery disease

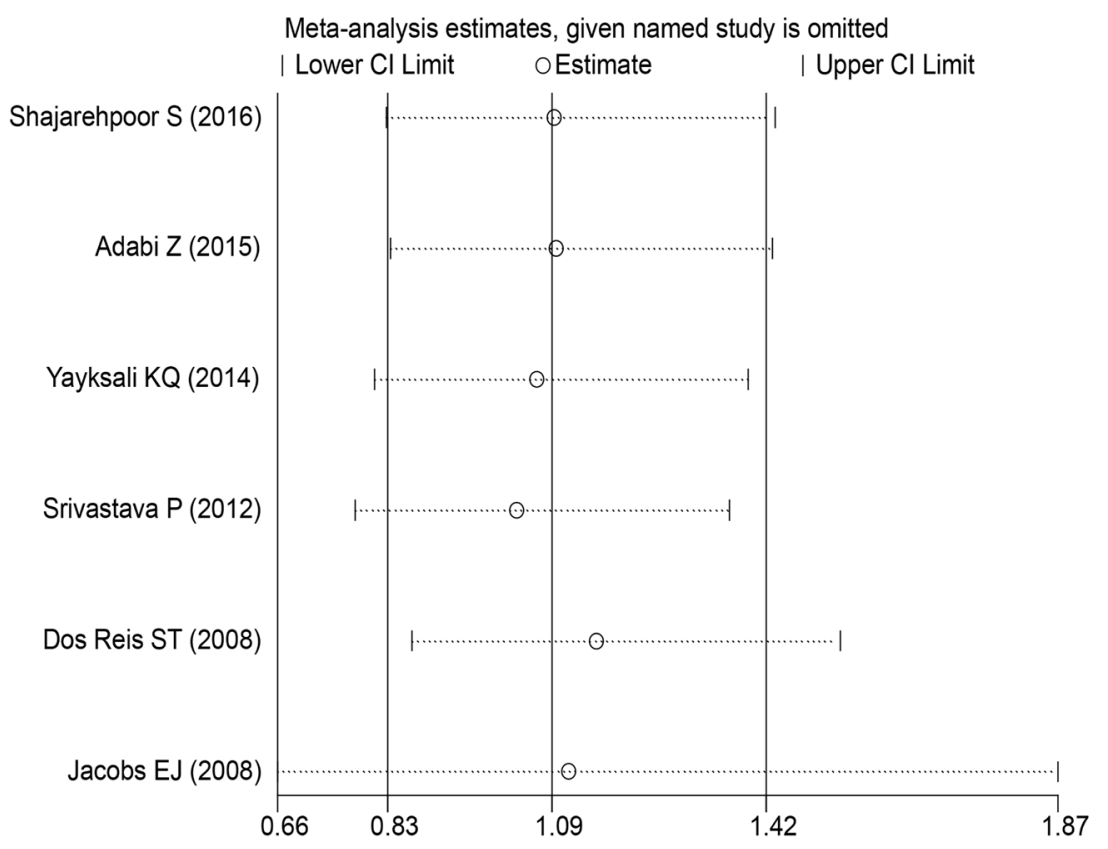

Figure 3: One-way sensitivity analysis of the $M M P 2-1306 C / T$ polymorphism with PCa risk. Individually removed the studies and suggested that the results of this meta-analysis were stable. 
risk [28] Whereas, other meta-analysis illustrated that the MMP-2-1306 polymorphism was significantly related to bladder cancer and head and neck cancer (HNC) risk among overall population [29-30], especially for Asian populations who were diagnosed as lung cancer [31]. The aforementioned contradictory results could be clarified that for certain population, distinct genes, loci within identical genes and various polymorphisms at same locus may affect different cancer susceptibilities [32]. Therefore, we performed the current meta-analysis to explore the potential correlation between MMP2-1306 $C / T$ polymorphism with $\mathrm{PCa}$ susceptibility in overall population and corresponding subgroups

MMPs are endopeptidases capable to degrade collagens from extracellular matrix (ECM). They are essential for proliferation, differentiation, morphogenesis, tissue remodeling and repair [33]. MMPs are engaged in cell cycle checkpoints control, cell adhesion and genomic instability, whose activity could be depressed by tissue inhibitors of metalloproteinases (TIMPs) [34]. MMPs and TIMPs could modulate the remodeling of ECM. The imbalance between MMPs and TIMPs may result in pathological processes such as arthritis and cancer [35]. Meanwhile, MMPs could alter the cellular microenvironment, which could facilitate tumor initiation and development [36]. Thus, excessive expression of MMPs may play crucial roles in cancer by facilitating ECM degradation. Notably, MMPs and TIMPs were proven to contribute to PCa risk. Circulating levels affected by single nucleotide polymorphisms (SNPs) of $M M P s$ gene promoter might lead to relevant biological responses. It has reported that $M M P-9$, rather than $M M P-1$ polymorphism variants were associated with pathological parameters in predicting the clinical outcome of prostate cancer patients [37-39]. As for MMP-2, it may be a poor prognosis indicator of $\mathrm{PCa}$ on account of serum/tissue over-expression in higher Gleason scores and cancerous invasion [40]. Previous study found that patients with CT genotype as well as T allele were significantly associated with 1.68-fold and 1.52-fold increased risk of PCa [41]. However, it was also reported that the genotype CT of $M M P 2$ was related to lower levels of $M M P 2$ mRNA and surprisingly lower circulating levels of $M M P 2$ were related to more aggressive $\mathrm{PCa}$ in culture cell lines. Thus, prostate cancer may be conversely responsible for lower gene/protein expression of MMP2 [42]. In view of multiple lines of contradictory results, we tried to explore the potential relationship in the current meta-analysis. To sum up, as most studies have presented definite relationships of $M M P$ polymorphisms in various types of cancer [43-45], MMPs may become putative therapeutic targets for cancer [46].

Actually, our meta-analysis has its limitations. Firstly, it is subjected to recall or selection bias of retrospective study. Secondly, only published studies might not provide sufficient evidences in this meta-analysis. Finally, our conclusion was checked by crude estimation rather than adjusted data. Therefore, other risk factors such as environmental effects, genetic factors and environmentgene interactions should also be taken into consideration in advanced researches. Meanwhile, the heterogeneity indicated there were potential or undiscovered factors in included publications. Moreover, several controls from eligible investigations didn't conform to HWE, which may

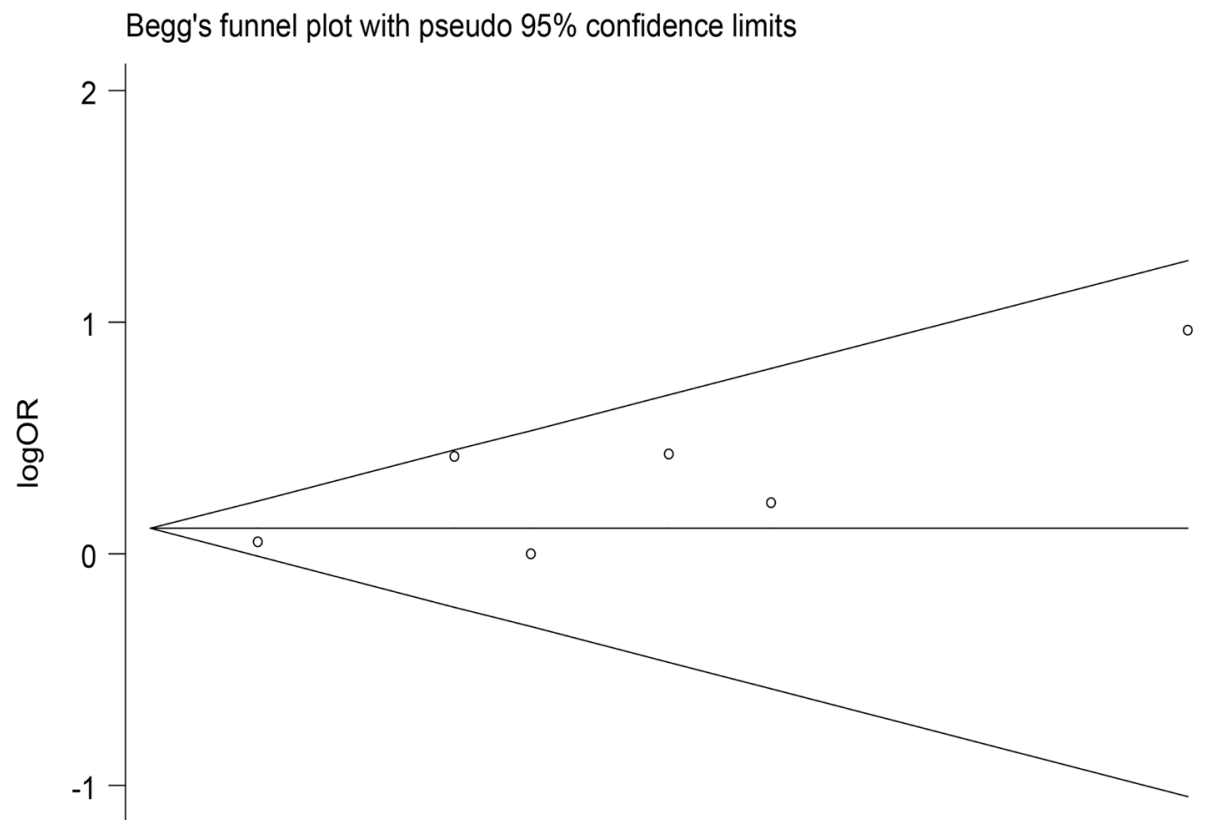

Figure 4: Begg's funnel plot to examine publication bias in allele of $M M P 2-1306 C / T$ polymorphism. Each circle corresponds to one study, and indicated that no publication bias existed. 
also influence the ultimate conclusion. Anyway, in spite of aforementioned limitations, a certain relationship of $M M P 2-1306 C / T$ polymorphism in PCa risk was identified in current meta-analysis.

In conclusion, the current study is the first original meta-analysis to address the correlation between the MMP2-1306 C/T polymorphism and PCa susceptibility. A marginally significant association was explored in overall population as well as the subgroups of Asian population and PCR-RFLP genotyped method. It presented that $M M P 2-1306$ C/T polymorphism might increase PCa risk to some extent. No association was detected in MMP2$1306 \mathrm{C} / \mathrm{T}$ polymorphism with any of the Gleason grading or pathological stage of PCa. However, in the future, welldesigned prospective studies with large cohort size and various SNPs are urgently necessary to verify our current findings.

\section{MATERIALS AND METHODS}

\section{Ethics statement}

Meta-Analysis of Observational Studies in Epidemiology (MOOSE) directions for reporting were used to perform the current meta-analysis [47]. No patient's privacy or clinical samples were involved in this study, hence the ethical approval was not required.

\section{Identification and eligibility of relevant studies}

Literature resources including PubMed, Cochrane Library, Embase, CBM and CNK were searched for eligible literatures, using the terms ("matrix metalloproteinases" or "matrix metalloproteinases 2" or "MMPs" or "MMP" or "MMP2"), ("prostatic cancer" or "prostate cancer" or "prostatic carcinoma" or "prostate carcinoma" or "PCa") and ("polymorphism" or "variant" or "mutation"). Last search of current investigation was updated on October $21^{\text {st }}, 2016$. There were no language restrictions. We identified other relevant articles by scanning all retrieved articles and reviews. Meanwhile, we treated them independently if different ethnicities were found in reported articles.

\section{Inclusion and exclusion criteria}

Studies followed the three criteria could be identified: (1) all included studies belonged to casecontrol or cohort studies; (2) relevant data to evaluate the correlations between $M M P 2$ polymorphisms with $\mathrm{PCa}$ risk were available; (3) PCa was histologically confirmed. Studies met the following three criteria were excluded: (1) the available data regarding about associations was absent;
(2) similar or duplicate study (When the same or similar cohort was applied, after careful examination, the most complete information was included); (3) other types of articles including reviews or abstracts.

\section{Data extraction}

In the light of inclusion and exclusion criteria, we extracted the relevant information from each eligible publication. If disagreements were noticed, we were clearly open to discuss by each other (K.Z. and M.C.), or reviewed by a third author (X.C.).

The data on first author, race, study country, number of case and control, publication year, genotyped method, study design, control source, whether there were certain associations between the paired groups, and $P$ value from Hardy-Weinberg equilibrium of control were collected by two authors independently. The Newcastle-Ottawa Scale consisted of selection, comparability of the groups and ascertainment of exposure was introduced to evaluate the included publication's quality. The NOS scores were 0 to 10 stars. If one included study obtained no less than 7 stars, it could be regarded as high-quality [48]. We have not contacted any author of the original researches even though the essential information could not be available. Besides, ethnicities were stratified into two groups: White and Asian population. Source of controls mainly derived from healthy population-based (PB) and benign prostatic hyperplasia $(\mathrm{BPH})$ population. Genetyped methods were divided into PCR-RFLP, Taqman and HRM.

\section{Statistical analysis}

We explored the relationship $M M P 2-1306 C / T$ polymorphism and PCa risk by applying STATA software (Version 12.0, Stata Corporation, TX). OR and 95\% CI were calculated for assessing the concrete relationships between $M M P 2-1306 C / T$ polymorphisms and PCa susceptibility. Varying models for genotyping, including allele comparison, dominant, recessive, homozygote and heterozygote models were applied to determine the associations with PCa risk. Meanwhile, the heterogeneity has been assessed via chi-square-based $\mathrm{Q}$ and $\mathrm{I}^{2}$ test across studies (no heterogeneity $\mathrm{I}^{2}<25 \%$, moderate heterogeneity $\mathrm{I}^{2}=25 \%-50 \%$, extreme heterogeneity $\mathrm{I}^{2}>50 \%$ ) [49]. In case of extreme heterogeneity ( $\mathrm{I}^{2}>50 \%$ or $P<0.01$ for $\mathrm{Q}$ test), we used random-effects (DerSimonian and Laird method) model [50]. Otherwise, fixed-effects (Mantel-Haenszel method) model was introduced [51].

One-way sensitivity analyses individually removed publications in meta-analysis were conducted to assess results' stability. It mainly explored the impact of specific study upon mixed OR.

The Begg's funnel plots where logOR was plotted against SE. $P$ value less than 0.05 indicated that there 
was a bias of study [52]. Additionally, different subgroups consisted of ethnicity, control source and genotyped approach were conducted.

\section{ACKNOWLEDGMENTS}

K.Z., X.C., M.Z., M.C. and L.Z. performed the literature search, data extraction, and statistical analysis and wrote the manuscript. J.Z., C.Y. and C.L. supervised the literature search, data extraction, analysis, M.C.; L.Z. and C.L. reviewed the manuscript. In addition, we are grateful to Dr. Pengfei Wei at University of Science and Technology of China for participating in the critical revision of this meta-analysis.

\section{CONFLICTS OF INTEREST}

The authors declare no competing financial interests.

\section{GRANT SUPPORT}

This work was supported by the National Natural Science Foundation of China $(81401518,81370856$, $81630019,81400757)$ and special cultivation project of AHMU (2013KJ14).

\section{REFERENCES}

1. Siegel RL, Miller KD, Jemal A. Cancer statistics, 2015. CA Cancer J Clin. 2015;65:5-29.

2. Stadler ZK, Thom P, Robson ME, Weitzel JN, Kauff ND, Hurley KE, Devlin V, Gold B, Klein RJ, Offit K. Genome-wide association studies of cancer. J Clin Oncol. 2010;28:4255-4267.

3. Salinas CA, Kwon E, Carlson CS, Koopmeiners JS, Feng Z, Karyadi DM, Ostrander EA, Stanford JL. Multiple independent genetic variants in the $8 \mathrm{q} 24$ region are associated with prostate cancer risk. Cancer Epidemiol Biomarkers Prev. 2008;17:1203-1213.

4. Zhang G, Zhu Y, Liu F, Gu C, Chen H, Xu J, Ye D. Genetic variants in insulin-like growth factor binding protein-3 are associated with prostate cancer susceptibility in Eastern Chinese Han men. Onco Targets Ther. 2015; 22:61-66.

5. Sun J, Zheng SL, Wiklund F, Isaacs SD, Purcell LD, Gao Z, Hsu FC, Kim ST, Liu W, Zhu Y, Stattin P, Adami HO, Wiley KE, et al. Evidence for two independent prostate cancer risk-associated loci in the HNF1B gene at 17q12. Nat Genet. 2008;40:1153-1155.

6. Huang SP, Lin VC, Lee YC, Yu CC, Huang CY, Chang TY, Lee HZ, Juang SH, Lu TL, Bao BY. Genetic variants in nuclear factor-kappa B binding sites are associated with clinical outcomes in prostate cancer patients. Eur J Cancer. 2013;49:3729-3737.

7. Chi N, Yun ZZ, Tan ZH, Li XZ, Chen BT, Liu J, Xu
LB, Ma KW, Li SX, Liu JF, Liu CX. Effect of p53 gene polymorphism on functions of prostate cancer cells. Genet Mol Res. 2015;14:11700-11709.

8. Srivastava P, Kapoor R, Mittal RD. Impact ofMMP-3 and TIMP-3 gene polymorphisms on prostate cancer susceptibility in North Indian cohort. Gene. 2013;530:273277.

9. Gialeli C, Theocharis AD, Karamanos NK. Roles of matrix metalloproteinases in cancer progression and their pharmacological targeting. FEBS J. 2011;278:16-27.

10. Sierevogel MJ, Pasterkamp G, de Kleijn DP, Strauss BH. Matrix metalloproteinases: a therapeutic target in cardiovascular disease. Curr Pharm Des. 2003;9:1033-1040.

11. Zayani Y, El Golli N, Zidi W, Guizani I, Boussairi S, Aloui S, Ayadi I, Ftouhi B, Feki M, Ben Romdhane N, Ben Sliman H. Inflammations mediators and circulating levels of matrix metalloproteinases: Biomarkers of diabetes in Tunisians metabolic syndrome patients. Cytokine. 2016;86:47-52.

12. Brown GT, Murray GI. Current mechanistic insights into the roles of matrix metalloproteinases in tumour invasion and metastasis. J Pathol. 2015;237:273-281.

13. Liao H, Wang Z, Deng Z, Ren H, Li X. Curcumin inhibits lung cancer invasion and metastasis by attenuating GLUT1/MT1-MMP/MMP2 pathway. Int J Clin Exp Med. 2015;8:8948-8957.

14. Tacheva T, Chelenkova P, Dimov D, Petkova R, Chakarov $\mathrm{S}$, Vlaykova T. Frequency of the common promoter polymorphism MMP2 -1306 $\mathrm{C}>\mathrm{T}$ in a population from central Bulgaria. Biotechnol Biotechnol Equip. 2015;29:351-356.

15. Price SJ, Greaves DR, Watkins H. Identification of novel, functional genetic variants in the human matrix metalloproteinase-2 gene: role of SP1 in allele-specific transcriptional regulation. J Biol Chem. 2001;276:75497558.

16. Munafo MR, Flint J. Meta-analysis of genetic association studies. Trends Genet. 2004;20:439-444.

17. Shajarehpoor Salavati L, Tafvizi F, Manjili HK. The association between MMP2 -1306 C $>\mathrm{T}$ (rs243865) polymorphism and risk of prostate cancer. Ir J Med Sci. 2017;186:103-111.

18. Adabi Z, Mohsen Ziaei SA, Imani M, Samzadeh M, Narouie B, Jamaldini SH, Afshari M, Safavi M, Roshandel MR, Hasanzad M. Genetic polymorphism of MMP2 gene and susceptibility to prostate cancer. Arch Med Res. 2015;46:546-550.

19. Yaykaşli KO, Kayikçi MA, Yamak N, Soğuktaş H, Düzenli S, Arslan AO, Metın A, Kaya E, Hatıpoğlu ÖF. Polymorphisms in MMP-2 and TIMP-2 in Turkish patients with prostate cancer. Turk J Med Sci. 2014;44:839-843.

20. Srivastava P, Lone TA, Kapoor R, Mittal RD. Association of promoter polymorphisms in MMP2 and TIMP2 with prostate cancer susceptibility in North India. Arch Med Res. 
2012;43:117-124.

21. Dos Reis ST, Pontes J Jr, Villanova FE, Borra PM, Antunes AA, Dall'oglio MF, Srougi M, Leite KR. Genetic polymorphisms of matrix metallo proteinases: susceptibility and prognostic implications for prostate cancer. J Urol. 2009;181:2320-2325.

22. Jacobs EJ, Hsing AW, Bain EB, Stevens VL, Wang Y, Chen J, Chanock SJ, Zheng SL, Xu J, Thun MJ, Calle EE, Rodriguez C. Polymorphisms in angiogenesis-related genes and prostate cancer. Cancer Epidemiol Biomarkers Prev. 2008; 17:972-977.

23. Inoue T, Nabeshima K, Kataoka H, Koono M. Feasibility of archival non-buffered formalin-fixed and paraffinembedded tissues for PCR amplification: an analysis of resected gastric carcinoma. Pathol Int. 1996;46:997-1004.

24. Solassol J, Ramos J, Crapez E, Saifi M, Mangé A, Vianès E, Lamy PJ, Costes V, Maudelonde T. KRAS mutation detection in paired frozen and Formalin-Fixed ParaffinEmbedded (FFPE) colorectal cancer tissues. Int J Mol Sci. 2011;12:3191-204.

25. Yang L, Li N, Wang S, Kong Y, Tang H, Xie X, Xie X. Lack of association between the matrix metalloproteinase-2 $-1306 \mathrm{C}>\mathrm{T}$ polymorphism and breast cancer susceptibility: a meta-analysis. Asian Pac J Cancer Prev. 2014;15:48234827.

26. Yang TF, Guo L, Wang Q. Meta-analysis of associations between four polymorphisms in the matrix metalloproteinases gene and gastric cancer risk. Asian Pac J Cancer Prev. 2014;15:1263-1267.

27. Liu D, Duan W, Guo H, Xu X, Bai Y. Meta-analysis of associations between polymorphisms in the promoter regions of matrix metalloproteinases and the risk of colorectal cancer. Int J Colorectal Dis. 2011;26:1099-1105.

28. Shi Y, Zhang J, Tan C, Xu W, Sun Q, Li J. MatrixMetalloproteinase-2 Polymorphisms and Incident Coronary Artery Disease: A Meta-Analysis. Medicine (Baltimore). 2015;94:e866.

29. Tao L, Li Z, Lin L, Lei Y, Hongyuan Y, Hongwei J, Yang L, Chuize K. MMP1, 2, 3, 7, and 9 gene polymorphisms and urinary cancer risk: a meta-analysis. Genet Test Mol Biomarkers. 2015;19:548-555.

30. Liu D, Guo H, Li Y, Xu X, Yang K, Bai Y. Association between polymorphisms in the promoter regions of matrix metalloproteinases (MMPs) and riskof cancer metastasis: a meta-analysis. PLoS One. 2012;7:e31251.

31. Wang J, Cai Y. Matrix metalloproteinase-2 polymorphisms and expression in lung cancer: a meta-analysis. Tumour Biol. 2012;33:1819-1828.

32. Ju W, Kim JW, Park NH, Song YS, Kim SC, Kang SB, Lee HP. Matrix metalloproteinase-1 promoter polymorphism and epithelial ovarian cancer: does ethnicity matter? J Obstet Gynaecol Res. 2007;33:155-160.

33. Kessenbrock K, Wang CY, Werb Z. Matrix metalloproteinases in stem cell regulation and cancer.
Matrix Biol. 2015;44-46:184-190.

34. Lozito TP, Jackson WM, Nesti LJ, Tuan RS. Human mesenchymal stem cells generate a distinct pericellular zone of MMP activities via binding of MMPs and secretion of high levels of TIMPs. Matrix Biol. 2014;34:132-143.

35. Shin YJ, Kim JH. The role of EZH2 in the regulation of the activity of matrix metalloproteinases in prostate cancer cells. PLoS One. 2012;7: e30393.

36. Ohbayashi H. Matrix metalloproteinases in lung diseases. Curr Protein Pept Sci. 2002; 3:409-421.

37. Schveigert D, Valuckas KP, Kovalcis V, Ulys A, Chvatovic G, Didziapetriene J. Significance of MMP-9 expression and MMP-9 polymorphism in prostate cancer. Tumori. 2013;99:523-529.

38. Albayrak S, Cangüven O, Göktaş C, Aydemir H, Köksal V. Role of MMP-1 1G/2G promoter gene polymorphism on the development of prostate cancer in the Turkish population. Urol Int. 2007;79:312-315.

39. Tsuchiya N, Narita S, Kumazawa T, Inoue T, Ma Z, Tsuruta H, Saito M, Horikawa Y, Yuasa T, Satoh S, Ogawa O, Habuchi T. Clinical significance of a single nucleotide polymorphism and allelic imbalance of matrix metalloproteinase-1 promoter region in prostate cancer. Oncol Rep. 2009;22:493-499.

40. Sauer CG, Kappeler A, Späth M, Kaden JJ, Michel MS, Mayer D, Bleyl U, Grobholz R. Expression and activity of matrix metalloproteinases- 2 and -9 in serum, core needle biopsies and tissue specimens of prostate cancer patients. Virchows Arch. 2004;444:518-526.

41. Xie T, Dong B, Yan Y, Hu G, Xu Y. Association between MMP-2 expression and prostate cancer: A meta-analysis. Biomed Rep. 2016;4:241-245.

42. Xu E, Lai M, Lv B, Xing X, Huang Q, Xia X. A Single nucleotide polymorphism in the matrix metalloproteinase-2 promoter is associated with colorectal cancer. Biochem Biophys Commun. 2004; 324: 999-1003.

43. Yan Y, Liang H, Li T, Li M, Li R, Qin X, Li S. The MMP-1, MMP-2, and MMP-9 gene polymorphisms and susceptibility to bladder cancer: a meta-analysis. Tumour Biol. 2014;35:3047-3052.

44. Zhang C, Li C, Zhu M, Zhang Q, Xie Z, Niu G, Song X, Jin L, Li G, Zheng H. Meta-analysis of MMP2, MMP3, and MMP9 promoter polymorphisms and head and neck cancer risk. PLoS One. 2013;8:e62023.

45. Hu C, Wang J, Xu Y, Li X, Chen H, Bunjhoo H, Xiong W, $\mathrm{Xu} \mathrm{Y,} \mathrm{Zhao} \mathrm{J.} \mathrm{Current} \mathrm{evidence} \mathrm{on} \mathrm{the} \mathrm{relationship} \mathrm{between}$ five polymorphisms in the matrix metalloproteinases (MMP) gene and lung cancer risk: a meta-analysis. Gene. 2013;517:65-71.

46. Yadav L, Puri N, Rastogi V, Satpute P, Ahmad R, Kaur G. Matrix metallo proteinases and cancer-roles in threat and therapy. Asian Pac J Cancer Prev. 2014;15:1085-1091.

47. Stroup DF, Berlin JA, Morton SC, Olkin I, Williamson GD, Rennie D, Moher D, Becker BJ, Sipe TA, Thacker SB. 
Meta-analysis of observational studies in epidemiology: a proposal for reporting. Meta analysis Of Observational Studies in Epidemiology (MOOSE) group. J Am Med Assoc. 2000;283:2008-2012.

48. Stang A. Critical evaluation of the Newcastle-Ottawa scale for the assessment of the quality of nonrandomized studies in meta-analyses. Eur J Epidemiol. 2010;25:603-605.

49. Higgins JP, Thompson SG. Quantifying heterogeneity in a meta-analysis. Stat Med. 2002;21:1539-1558.
50. DerSimonian R, Laird N. Meta-analysis in clinical trials. Control Clin Trials. 1986;7:177-188.

51. Mantel N, Haenszel W. Statistical aspects of the analysis of data from retrospective studies of disease. J Natl Cancer Inst. 1959;22:719-748.

52. Begg CB, Berlin JA. Publication bias and dissemination of clinical research. J Natl Cancer Inst. 1989;81:107-115. 